TABlB V.-Sites of Chest Pains Other than Effort Angina

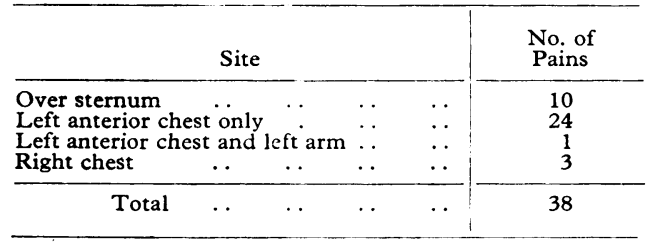

it, but the point of immediate practical importance is not what we think it is but what patients think it is.

In reply to the question "Do you believe your pain is due to heart disease?" $73 \%$ of patients with effort angina and $71 \%$ of patients with left chest pain said "Yes." Thus patients generally believe left chest pain is due to heart disease, and, since it dates from an illness with severe chest pain, this is scarcely surprising.

The point I would stress is that these painful sequels of myocardial infarction are exceedingly common. Patients don't always volunteer them but they do often worry about them. Part of the treatment after myocardial infarction is to get the patient back to work physically fit and mentally unperturbed. This process of rehabilitation should include specific inquiry about chest pains, bearing in mind that these pains are often multiple and that the patient may find left chest pain and other non-anginal pains more frightening and disabling than effort angina, which he may come to tolerate as a predictable and familiar companion. Even though one may not be able to cure his pain, restoration of confidence to a patient with chest pain after myocardial infarction is a most rewarding therapeutic exercise.

\section{Conclusion}

These, then, are some of the sequels of myocardial infarction.

In the acute stage, monitoring of the circulation and resuscitation may prove useful though their place in routine practice is still uncertain.

Cardiogenic shock presents an outstanding challenge.

The long-term anticoagulant problem is falling into perspective. It seems clear that anticoagulants, if useful at all, will prove of pretty restricted value.
Imperfect rehabilitation after myocardial infarction produces a toll of misery, and this is often triggered by symptoms of chest pains whose mechanisms we have yet to discover.

Having sketched these headlines, I would end with the perhaps obvious comment that, though it is the sequels which engage us in day-to-day practice, in fact in treating them we are shutting the stable door after the horse has gone. Myocardial infarction, this epidemic disease of our time, presents above all else a problem in preventive medicine.

\section{REFERENCES}

Arnott, W. M. (1961). In Anticoagulants and Fibrinolysins, edited by R. L. Macmillan and J. F. Mustard. Pitman, London.

Beck, C. S., Weckesser, E. C., and Barry, F. M. (1956). f. Amer. med. Ass., 161, 434.

Bjerkelund, C. J. (1957). Acta med. scand., Suppl. 330.

- (1961). In Anticoagulants and Fibrinolysins, edited by R. L. Macmillan and J. F. Mustard. Pitman, London.

Brown, K. W. G., Macmillan, R. L., Forbath, N., Meligrana, F., and Scott, J. W. (1963). Lancet, 2, 349.

Scott, J. Noble, E. J. G. (1961). In Anticoagulants and Fibrinolysins, edited by R. L. Macmillan and J. F. Mustard. Pitman,

Clausen, J., Andersen, P. E., Andersen, P., Gruelund, Sv., Harslof, E., Andersen, U. H., Jorgensen, J., and Mose, C. (1961). Ugeskr. Lag., 123, 987 .

Denborough, M. A., Goble, A. J., Lovell, R. R. H., and Nestel, P. J. (1962). Med. Э. Aust., 2, 937.

Dock, W. (1929). Amer. Heart F., 4, 709.

Engelberg, H., Kuhn, R., and Steinman, M. (1956). Circulation, 13, 489. Feifar, Z. (1959). Adv. Cardiol., 2, 108. Karger, Basel, New York.

Freis, E. D., Schnafer, H. W., Johnson, R. L., and Shreiner, G. E. (1952). F. clin. Invest., 31, 131.

Goble, A. J., Adey, G. M., and Bullen, J. F. (1963). Med. F. Aust., 11 975.

Harvald, B., Hilden, T., Letman, H., Lund, E., Thaysen, E. H., and Worning, H. (1961).' Ugeskr. Lag., 123, 983.

Julian, D. G., Valentine, P. A., and Miller, G. G. (1964). Med. F. Aust., $1,433$.

Kannel, W. B., Dawber, T. R., Kagan, A., Revorskie, N., and Stokes, J. (1961). Ann. intern. Med., 55, 33.

Lovell, R. R. H. (1963). Med. Ұ. Aust., 11, 915.

Denborough, M. A., Nestel, P. J., and Goble, A. J. (1964). Arch. intern. Med., 113, 267.

Macmillan, R. L., Brown, K. W. G., and Watt, D. L. (1960). Canad. med. Ass. F., 83, 567 .

Medical Research Council (1959). Brit. med. f., 1, 803.

Nast, P. R., Pennypacker, C. S., and Wagner, J. A. (1960). Circulation, $22,138$.

Paul, O., Lepper, M. H., Phelan, W. H., Dupertuis, G. W., Macmillan, A., McKean, H., and Park, H. (1963). Circulation, 28, 20.

Robinson, J. S., Sloman, G., and McRae, C. (1964). Med. F. Aust., 1, 427.

Rose, G. A. (1962). Bull. Wld Hlth Org., 27, 645.

Strand, M. W., and Feil, H. S. (1948). Amer. Heart f., 35, 910.

\title{
Nosematosis, a Microsporidial Infection of Rodents and Other Animals, Including Man
}

\author{
R. LAINSON,* PH.D. ; P. C. C. GARNHAM,* C.M.G., M.D., F.R.S. \\ R. KILLICK-KENDRICK*; R. G. BIRD,* PH.D., M.B.
}

[With Special Plate]

Brit. med. F., 1964, 2, 470-472

The natural occurrence of aggregations of small organisms in the brain of mammals has been noted with increasing frequency over the past fifty years. Such parasites have variously been described as Toxoplasma gondii, Trypanosoma cruzi, " $\mathrm{M}$ " organism, or Encephalitozoon.

* From the London School of Hygiene and Tropical Medicine, London.
The identity of Toxoplasma gondii and Trypanosoma cruzi presents no serious problem in adequately prepared material, but the nature of Encephalitozoon has puzzled workers since the time it was first described and named by Levaditi et al. (1923) in the brain of rabbits suffering from encephalitis.

A connexion between Encephalitozoon and human disease was soon sought by these same authors (Levaditi et al., 1924a); 
they claimed that a similar parasite was associated with rabies and called it E. rabiei. Doerr and Zdansky (1924) found similar organisms in the brains of rabbits that they had inoculated with material from patients suffering from encephalitis lethargica. Again, Garnham and Roe (1954) discovered E. muris in the capsule of the liver and spleen of mice inoculated with leukaemia material.

In all these observations there was no definite proof that the parasite originated from the hurnan material, for in no case was it established that the experimental animals were not already infected. Much later, however, Matsubayashi et al. (1959) presented conclusive evidence of human infection with encephalitozoa when they saw and recovered the organism in the cerebrospinal fluid and urine of a Japanese boy suffering from fever accompanied by cerebral symptoms. They isolated the parasite by inoculating cerebrospinal fluid and urine into laboratory mice, and in this case 30 control mice remained negative.

The true nature of Encephalitozoon has remained obscure until quite recently. Levaditi et al. (1924b) regarded the parasite as a microsporidian and described binucleate forms as "pan-sporoblasts," but Wenyon (1926) remained unconvinced and stressed the necessity of demonstrating the presence of a polar capsule and filament before this view could be accepted. Biocca (1949) and Levine (1961) allied Encephalitozoon with Toxoplasma, but Lainson $(1954,1955)$ studied the parasite from rats and rabbits and commented on the presence of a polar vacuole "reminiscent of the polar capsule of the Cnidosporidia" (Microsporidia). He also described division stages similar to those seen by Levaditi et al.

The position was clarified when Nelson (1962) described the extrusion of a filament from " oval bodies" strongly resembling encephalitozoa in the ascitic fluid of laboratory mice.

This important observation, together with the recent demonstration of undoubted microsporidial (Thelohania spp.) infections in the brain of some wild rodents (Doby et al., 1963), has prompted us to make further observations on the strain of Encephalitozoon so commonly found in our laboratory rats, with particular reference to its life-cycle and fine structure.

\section{Materials and Methods}

Nine years had elapsed since Encephalitozoon was last demonstrated in the laboratory rats at our field station (Winches Farm, St. Albans). It is perhaps some measure of the efficiency of the natural transmission of the parasite that we should still find four out of six rats we examined to be infected. Strains were isolated by the inoculation of brain suspensions from these animals into mice, by the intraperitoneal route, and maintained by similar subinoculation of peritoneal exudate into further mice 14 to 21 days later.

Stained preparations for the study of the developmental stages of the parasite were made from animals which had been infected from 12 to 21 days previously. The mice were killed, the abdominal cavity was opened, and excess peritoneal exudate was removed with a sterile pipette. Clean slides were then pressed on to the exposed viscera: in this way we not only obtained abundant exudate cells on the slides but also flattened sheets of peritoneum, in the cells of which the organisms were much more clearly seen.

Best preservation of the parasite was found after the wetfixation of smears in aqueous Bouin's fixative, staining by Giemsa's method, and differentiation in graded acetone-xylene mixtures.

Many different methods were tried to extrude a polar filament from the spores. Pressure under a coverslip, admixture of peritoneal exudate with water, addition of washed spores to mouse peritoneal fluid, slow desiccation followed by rapid hydration, and incubation for long periods in artificial gastric juices were all unsuccessful. Finally, the immediate extrusion of the filament was achieved in approximately $50 \%$ of the spores by the method of Lom and Vávra (1963a) in their work on other microsporidia. A solution was prepared of $2 \mathrm{ml}$. of a $20 \mathrm{vol}$. solution of hydrogen peroxide B.P. in $100 \mathrm{ml}$. of distilled water and a drop placed on a clean slide. A neighbouring drop of the infected peritoneal exudate was quickly mixed with it and the whole mounted under a wax-ringed coverslip. In such preparations, however, the depth of fluid and the drifting movements of the spores rendered photography impossible: to overcome this difficulty other preparations were made on slides coated with agar-a method devised by Smiles (Ormerod, 1958) for the immobilization of trypanosomes during phasecontrast examination.

The paucity of the organisms in the infected animals presented a serious obstacle to the application of routine electron microscope techniques, but we eventually overcame this by using the graticule-slide technique of Bird et al. (1964). Thin smears of the infected peritoneal exudate were made on such slides and at once fixed in a variety of fixatives, including that of Rhodin and Zetterqvist (Mercer and Birbeck, 1961) with a final concentration of $1 \%$ osmium tetroxide. After the slides had been washed in the buffer solution they were mounted in $70 \%$ spirit under wax-sealed coverslips and examined by phasecontrast microscopy. Suitable aggregations of parasites could then be selected for embedding in Araldite and sectioning.

\section{Results}

\section{Behaviour of "Encephalitozoon" in Experimentally Infected Mice}

Minor variations were at first thought to exist among our different isolates of the parasite, largely in the degree of ascites produced in the mice. Such variations, however, were seen within batches of animals inoculated with the same strain at the same time and are probably connected with different individual response on the part of the mice.

Proliferation of the parasites in the cells of the peritoneum and exudate reaches a maximum from two to three weeks after the mouse has been infected. At this time some mice become very distended and as much as 1-3 ml. of ascitic fluid can be withdrawn from a single animal ; on the other hand, the abdominal cavity of other mice may remain relatively dry or show only a little viscous exudate. The number of parasites remains fairly constant, however, regardless of the degree of ascites, with an average infection rate of $2.5 \%$ of the exudate cells.

From about the fourth week of infection the number of parasites in the peritoneal cavity dwindles, and after this time few or none can be found there. In animals with infections of several months' duration, however, large aggregations of densely packed spores can be readily found in sections of the brain (Specia! Plate, Diagram, J ; Fig. 11). Such aggregations are apparently not bounded by any membrane, and we have frequently found evidence of their rupture in foci of intense cellular reaction, associated with scattered spores, in the brain of naturally infected rats, hamsters, and multi-mammate rats.

\section{Developmental Cycle of " Encephalitozoon"}

The Dias ram (Special Plate) shows our interpretation of the complete de elopmental cycle of the rat strain of Encephalitozoon. The drawings were all made from actual parasites and have been placed in what we feel to be the natural sequence of events. A seiies of unretouched photomicrographs of both living parasites seen by phase-contrast microscopy and developmental stages as inen in Bouin-fixed, Giemsa-stained smears is also included as supporting evidence (Special Plate, Figs. 1-10).

Fig. 1 shows small group of Encephalitozoon spores within a monocyte, as, seen in a living preparation by phase- 
contrast microscopy. The polar capsule is clearly visible in some of the parasites.

Fig. 2 illustrates a larger aggregation of spores in a wet preparation, immediately after the addition of hydrogen peroxide. The host cell has ruptured and the majority of the spores have shot out their polar filament, which has a maximum length of about $24 \mu$. In one preparation we found the sporoplasm still attached to the distal end of the filament in about one-third of the extruded spores, and we were able to make drawings of these (Special Plate, Diagram, A). The sporoplasm has a rounded, almost vesicular appearance and a diameter of about $1.5 \mu$. In many instances we observed two darker spots in the sporoplasm which were regarded as nuclei.

Once it has entered a new cell, the parasite undergoes a phase of division to produce oval or slightly irregular bodies, measuring 2-6 $\mu$ by $1-3 \mu$ and containing one or two nuclei (Special Plate, Diagram, B-G; Figs. 3-6a). The cytoplasm of these dividing forms stains a bright blue with Giemsa's stain, and there is sometimes a paler halo about the nuclei (Fig. 4). When a number of divisions have taken place, some of the uninucleate products (sporonts) divide no more, but each secretes a rigid spore capsule (Special Plate, Diagram, H ; Fig. 7).

Typically the resulting spores (Special Plate, Fig. 10) are oval, and measure about 2.5 by $1.5 \mu$. The internal structure is seen merely as an undifferentiated, purple-red mass toward the centre of the spore. It is at this spore stage that Encephalitozoon becomes strongly Gram-positive, and this property can be most effectively utilized in detecting very scanty parasites in either smears or sections of tissues from infected animals.

As the spores begin to pack the infected cell the continuing dividing forms become much distorted (Special Plate, Diagram, $\mathrm{H}$; Figs. 7 and 9); at the periphery of the expanding mass they are flattened against the host-cell cytoplasm, while more centrally they are indented in leaf-like shapes by the pressure of the surrounding spores. Ultimately the host-cell membrane is stretched to its limit (Special Plate, Fig. 8) and ruptures (Diagram, A ; Figs. 9 and 10); the spores are thus released and the cycle is recommenced.

Presumably the renewed cycle of development may be initiated by the extrusion of the sporoplasms and their entry into new cells, or, more simply, by the phagocytosis of the existing division stages, which are also released along with the spores (Special Plate, Diagram, A ; Fig. 9).

Infection finally extends to various tissues of the body, particularly the brain, where large masses of spores ("cysts") may be found (Special Plate, Diagram, J ; Fig. 11).

Electron micrographs (Special Plate, Figs. 12 and 13) of mature spores in tangential and longitudinal section clearly confirmed the presence of the filament with five coils. To date, a limited amount of material, fixed in the modified Rhodin-Zetterqvist fixative, has been studied. From this it is clear that we are faced with difficulties in achier ing adequate penetration of the fixative through the thick spore capsule. Details of other internal structures are therefore uncertain and their demonstration must await improved techniques.

\section{Discussion}

Our findings completely confirm the microsporioifl nature of "Encephalitozoon." The Gram-positive spores have zit thick shell, a single polar vacuole, and, under suitable conditions, extrude long polar filaments at the end of which is attached the infective sporoplasm. We think that the extrusion occurs irs nature when the animal-mouse, man, or other mammal-swallows the spore, and that the polar filament shoots the sporoplasm into the gut epithelium. In this tissue, and eventually else $x$ here in the body, development continues by binary fission of the organism and the production of oval sporonts from earn of which a single spore is differentiated. The electron microscope reveals that the spore has a fine structure similar to that described by Huger (1960) and Lom and Vávra (1963b) for other species of microsporidia.

, The next question that arises is the correct name of the organism. The parasite clearly belongs to the Nosematidae, which includes the causative agents of bee disease ("Isle of Wight disease") and silkworm disease (pébrine). The first species in mammals was described by Levaditi et al. (1923) under the name of Encephalitozoon cuniculi; these workers showed that several animals were capable of being infected, and although a variety of names have been used to designate similar organisms in different animals it appears to us that the organisms all belong to a single species. We propose, therefore, that the correct name of the organism, as found in rats, multi-mammate mice, hamsters, mice, and rabbits in England (at our field station, St. Albans) and in man (as described by Matsubayashi et al. (1959) in Japan, is Nosema cuniculi (Levaditi et al., 1923). In this way we follow the current practice of including all the so-called species of Toxoplasma, equally widespread in the animal kingdom, under the single specific name of $T$. gondii.

Nosema cuniculi has been shown to be capable of producing a severe illness with cerebral involvement in man. The kidneys are also affected, and a generalized infection presumably exists. The parasite is extremely common in rodents, and it is not improbable that nosematosis is a zoonosis affecting man from this source, with the production of subpatent infections in quantity, and less often of an undiagnosed disease of virulent type, with encephalitic or other symptoms. There is a close parallel here with toxoplasmosis, and an obvious next step will be to devise a serological reaction capable of diagnosing past or present infections of Nosema cuniculi.

\section{Summary}

The widely distributed protozoon parasite "Encephalitozoon" was proved to be a microsporidian by $(a)$ the characters of its developmental cycle, and $(b)$ its fine structure as demonstrated by electron microscopy.

It is suggested that the correct name of the organism is Nosema cuniculi (Levaditi et al., 1923) as found in rats, rabbits, and man.

The potential importance of nosematosis as a zoonosis is emphasized. Transmission is thought to take place from a rodent source to man, with the production of an acute illness accompanied by cerebral or generalized symptoms.

\section{REFERENCES}

Biocca, E. (1949). Riv. Parassit., 10, 73.

Bird, R. G., Molloy, J. O., and Ormerod, W. E. (1964). In press. Doby, J. M., Jeanes, A., and Rault, B. (1963). C.R. Acad. Sci. (Paris),

Doerr, R., and Zdansky, E. (1924). Schweiz. med. Wschr., 54, 151. Garnham, P. C. C., and Roe, F. J. C. (1954). Trans. roy. Soc. trop. Med. Hyg., 48, 1.

Huger, A. (1960). \%. insect Path., 2, 84.

Lainson, R. (1954). Trans. roy. Soc. trop. Med. Hyg., 48, 5.

- (1955). "Studies on the Epidemiology of Toxoplasma gondii in England." Thesis for the degree of Ph.D. (Faculty of Science), University of London.

Levaditi, C., Nicolau, S., and Schoen, R. (1923). C.R. Acad. Sci. (Paris), 177,985 .

- (1924a). C.R. Soc. Biol. (Paris), 110, 398.

Levine N - (1924b). Ibid., 110, 662 .

Levine, N. D. (1961). Protozoan Parasites of Domestic Animals and Man p. 341. Burgess Publishing Co., Minneapolis, U.S.A.

Lom, J., and Vávra, J. (1963a). Acta protozool., 1, 81.

L (1963b). Ibid., 1, 279.

Matsubayashi, H., Koike, T., Mikata, I., Takei, H., and Hagiwara, S. (1959). Arch. Path., 67, 181.

Mercer, E. H., and Birbeck, M. S. C. (1961). Electron Microscopy : a Handbook for Biologists, p. 54. Blackwell, Oxford.

Handbook for Biologists, p. 54. Blackwell, Oxford.
Nelson, J. B. (1962). Proc. Soc. exp. Biol. (N.Y.), 109, 714.

Ormerod, W. E. (1958). f. gen. Microbiol., 19, 271.

Wenyon, C. M. (1926) Protozoology, vol. 2, p. 756. Baillière, Tindall and Cox, London. 


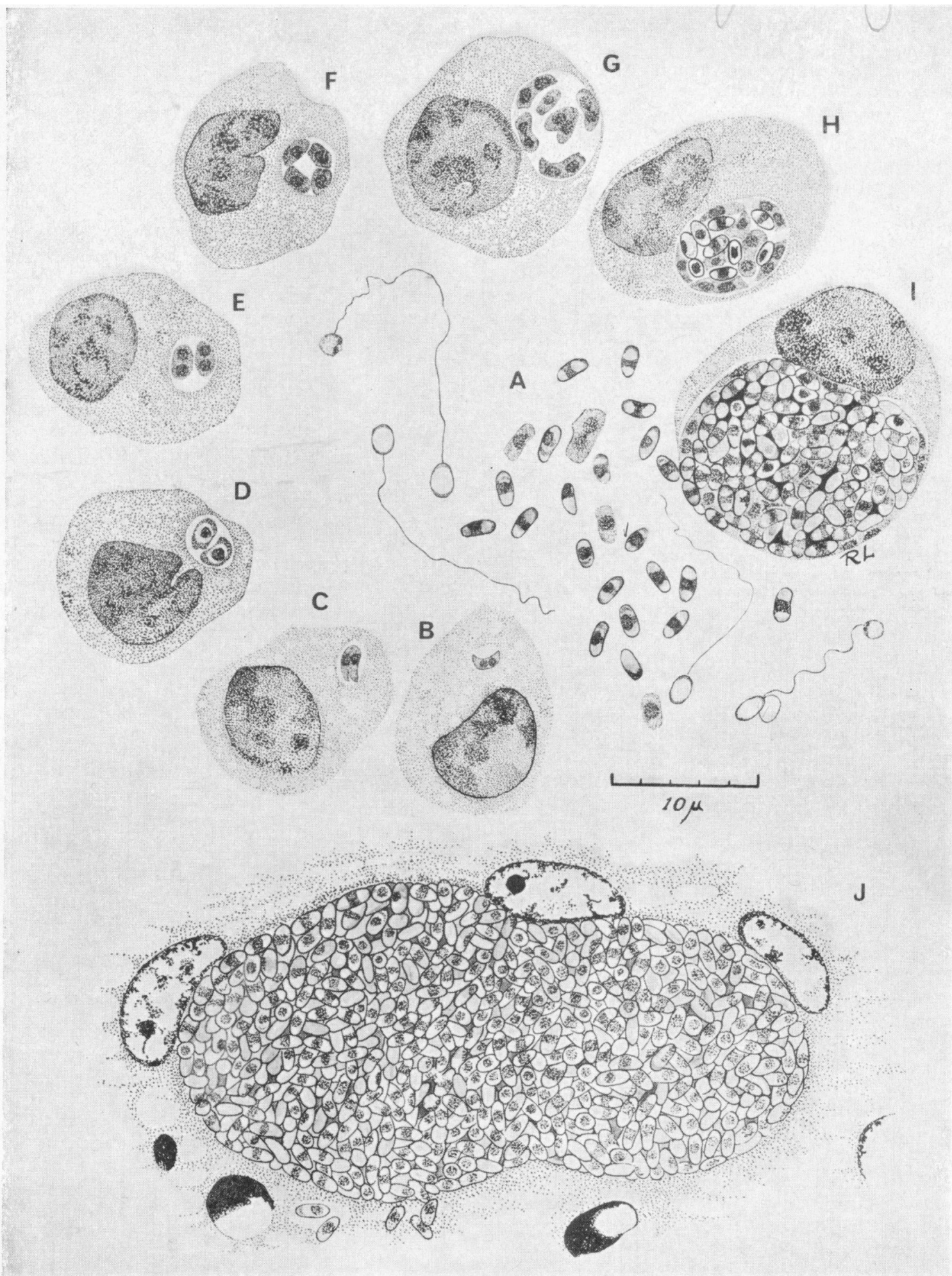

Diagram showing the developmental cycle of Nosema cuniculi (syn. Encephalitozoon cuniculi) as seen in the peritoneum and peritoneal fluid cells of experimentally infected mice. Based on drawings of actual parasites. (A) Liberation of both mature spores and division stages following the rupture of a heavily infected cell. A number of spores have extruded their polar filaments and in two instances the binucleated sporoplasm is still attached. (B-G) Entry of the sporoplasm into a new host cell, initiating the phase of binary fission, producing sporonts (H) Differentiation of sporonts into spores, one sporont giving rise to a single spore by the secretion of a thick capsule. (I) A host monocyte packed with both divione sporont giving rise to a single spore by the secretion of a thick capsule. (I) A host monocyte packed with both divi-
sion forms of the parasite and mature spores. (J) Large aggregation of densely packed spores of $N$. cuniculi in the brain of a mouse infected four months previously by the intraperitoneal route. 


\section{R. LAINSON ET $A L .:$ NOSEMATOSIS}

Photomicrographs $(x 1,800)$ of the developmental cycle of $N$. cuniculi as seen in the peritoneal cells of experimentally infected mice. Figs. 1 and 2 are from living material under phase-contrast microscopy. Figs. 3-7 are from Bouin-fixed, Giemsa-stained smears.

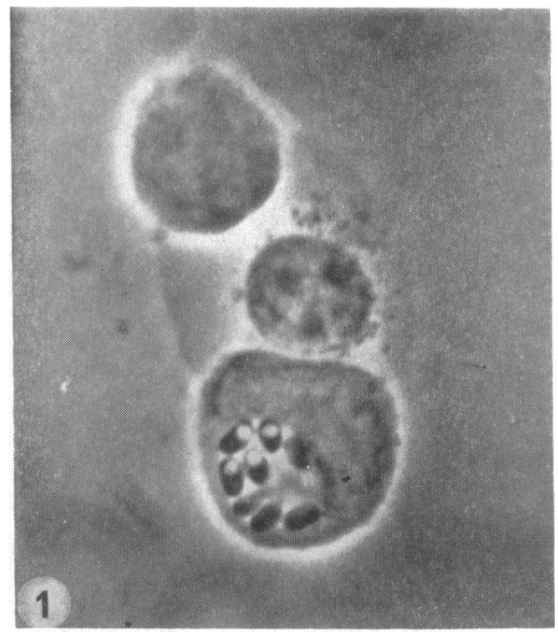

Fig. 1.-A small group of spores within a monocyte; polar vacuoles can be seen in four Individuals.

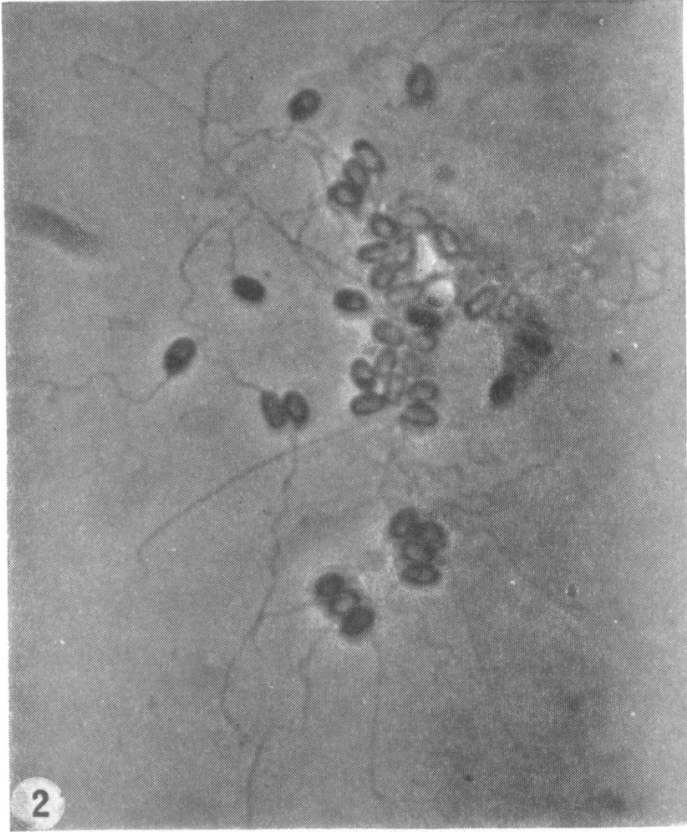

FIG. 2.-Rupture of the host cell and liberation of spores which have now extruded their polar filaments. From material treated with hydrogen peroxide.
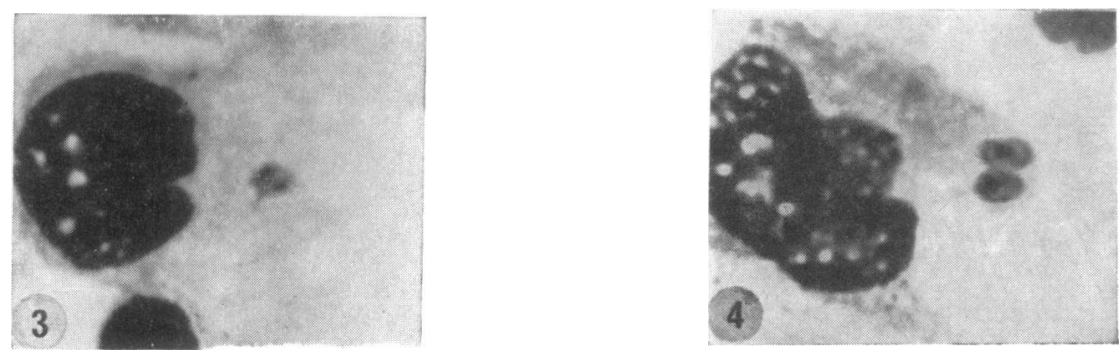

Figs. 3-6a.-Entry of the binucleate sporoplasm into a new host cell and the phase of binary division leading to the production of sporonts.

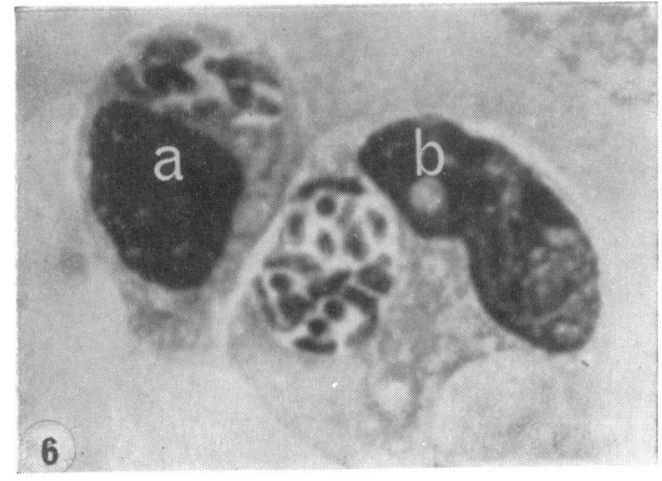

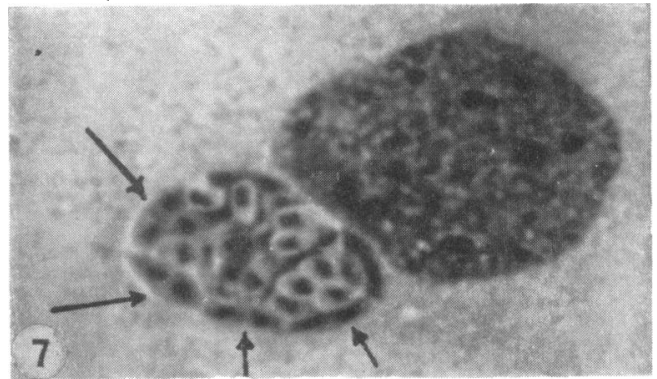

FIG. 7.-Early differentiation of sporonts into spores within a cell of the peritoneum. The dividing form (arrowed) continue to produce further sporonts and are becoming somewhat flattened by the increasing pressure within the parasitic mass. 


\section{R. LAINSON ET $A L$ : : NOSEMATOSIS}

Photomicrographs $(\times 1,800)$ of the developmental cycle of $N$. cuniculi as seen in the peritoneal cells of experimenta". infected mice. Bouin-fixed, Giemsa-stained smears.

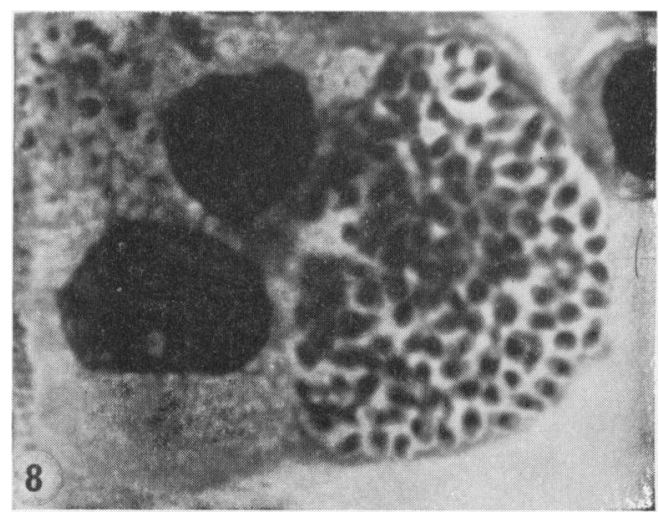

Fig. 8.-Monocyte packed with spores and developmental forms of $N$. cuniculi.

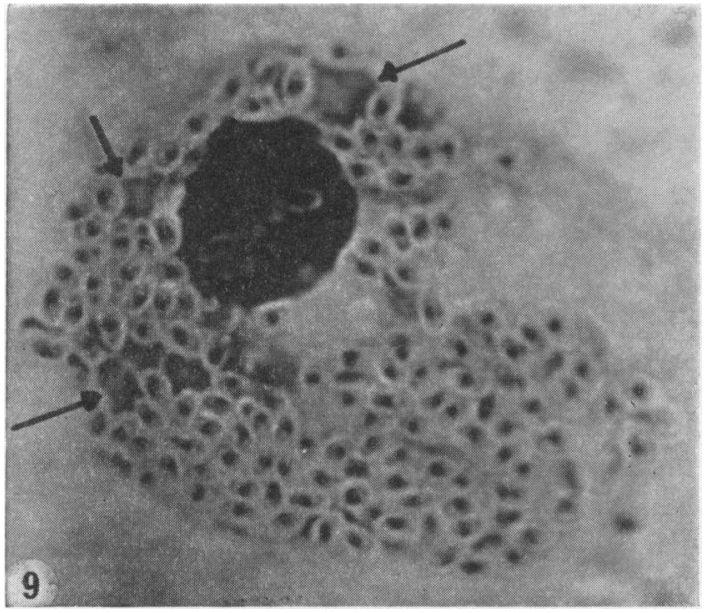

FIG. 9.-Rupturing monocyte releasing large numbers of mature spores and dividing forms (arrowed) of $N$. cuniculi.

Section of brain (Fig. 11) from a hamster naturally infected with $N$. cuniculi, showing a dense mass of spores. Note lack of host cell reaction. Tissue fixed in Carnoy's fluid, sectioned at $4.0 \mu$ and stained by the GiemsaColophonium method.

Electron micrographs (Figs. 12 and 13) of $N$. cuniculi mature spores. These longitudinal and tangential sections clearly show the spirally coiled filament. $(\times 75,000$.

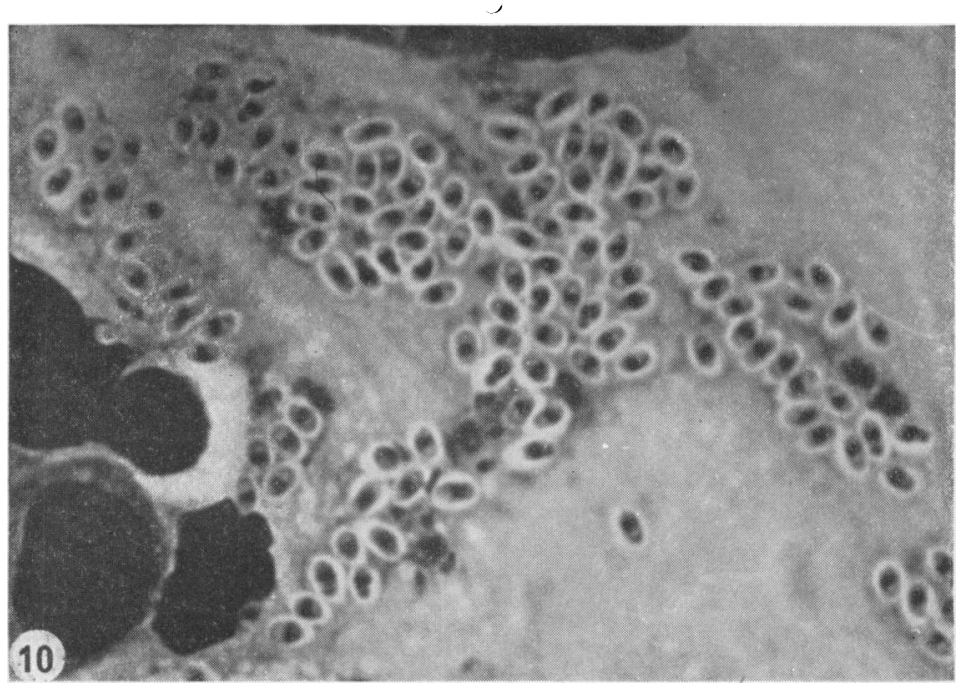

FIG. 10.-Freed spores.
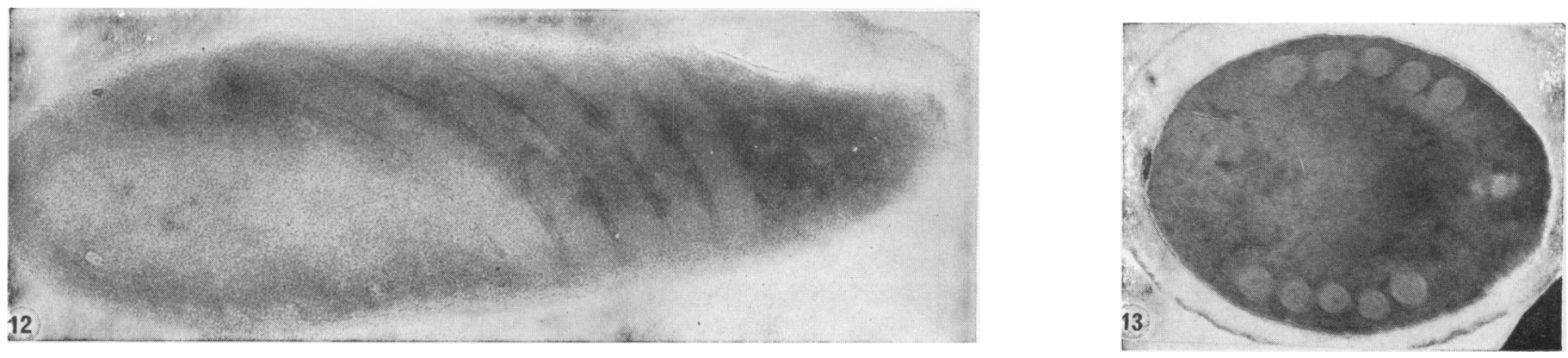